\title{
LONG TERM CLOUD-RESOLVING NUMERICAL SIMULATIONS OF THE WESTERN PACIFIC OCEAN-ATMOSPHERE COUPLED SYSTEM
}

\author{
Alexandre Araújo Costa' \\ Recebido em 25 abr. 2003 / Aceito em 6 jan., 2004 \\ Received Apr. 25, 2003 / Accepted Jan. 6, 2004
}

\section{ABSTRACT}

What is the role of the salt stratification in the maintenance of high sea surface temperatures (SSTS) over the Western Pacific? In order to investigate the salinity effect on the ocean temperature over that region, two 70-day coupled simulations were performed, with and without salt-stratification and freshwater flux, using a cloud-resolving model (CRM) coupled to an ocean model with high horizontal and vertical resolution. No evidence was found that, at least in such a timescale, the salt-stratification helps the maintenance of high SSTs over the Western Pacific.

Keywords: Coupled cloud-resolving model, air-sea interaction

\section{RESUMO}

Qual o papel da estratificação na salinidade para a manutenção das altas temperaturas na superfície do mar (TSMs) sobre o Pacífico Oeste? Com vistas a investigar 0 efeito da salinidade na temperatura do oceano sobre aquela região, duas simulações acopladas de 70 dias foram realizadas, com e sem estratificação de salinidade e fluxo de água doce, usando um modelo de nuvens (CRM) acoplado a um modelo oceânico com alta resolução horizontal e vertical. Não foram encontradas evidências, pelo menos na escala de tempo investigada, de que a estratificação na salinidade favoreça a existência de TSMs elevadas sobre o Pacífico Oeste.

Palavras-chave. Modelo de nuvens acoplado, interação oceano-atmosfera 


\section{INTRODUCTION}

The often-small variations in the sea surface temperatures (SSTs) over tropical regions suggest the existence of regulating mechanisms in order to keep their values bounded. Many theories have been proposed in order to explain how tropical SSTs are controlled.

Graham and Barnett (1987) proposed that evaporative cooling and blocking of solar radiation could act as controlling factors for the SST. Later, a theory of a cirrus-based "thermostat" for the SSTs was proposed by Ramanathan and Collins (1991). Since the ocean below cloudy air receives less solar radiation, it tends to cool, while heating occurs in clear regions. Therefore, long-lived optically-thick cirrus clouds that reflect significant amounts of solar radiation, generated as a byproduct of deep convection, would be responsible by changes in the ocean radiation budget. However, in opposition to Ramanathan and Collins (1991), Fu and others (1992) found no relation between cirrus and SSTs. They also criticized the "local thinking" behind the cirrusthermostat theory arguing that air-sea interaction should be strongly non-local.

As it became clear that no simple framework could explain the intricate relationship between tropical convection and SST, Waliser and Graham (1993) proposed that the regulation of the surface temperature of tropical oceans is made by an "imperfect thermostat". In fact, as SSTs increase, the atmospheric column is destabilized and, in turn, convection results in decreased surface insolation (as well as enhanced surface fluxes), suggesting that an "equilibrium state" could be reached. However, according to Waliser and Graham's point of view, internally generated atmospheric variability produces fluctuations in convection regardless of the SSTs. Such variability would disturb the system, preventing the SST-convection equilibrium to be maintained, particularly on short time scales, shaping an imperfect regulation.

Webster (1994) also discussed the regulation of SSTs by convection and introduced new ingredients. Arguing that the oceanatmosphere interaction goes beyond radiational and evaporational regulation, he calls for the inclusion of the effect of freshwater flux in the conceptual model of SST regulation, particularly over the western Pacific warm pool (WPWP). Since deep convection produces a large freshwater flux, Webster postulates that, due to the stabilizing effect of precipitation in the upper ocean, radiant heating is limited to a fresh, shallow layer. A detailed description of the shallow WPWP mixed-layer (only $30 \mathrm{~m}$ deep on average) was made by Lindstrom and others (1987) and Lukas and Lindstrom (1991).

Since the buoyancy flux associated with precipitation is large in the WPWP, the isothermal layer is often deeper than the mixed layer, which is a key factor to maintain the warm SSTs. The existence of a saltstratified layer between the mixed-layer and the bottom of the isothermal layer prevents the entrainment of cool water from below in the mixedlayer. Such a salt-stratified layer acts as a "barrier" for heat fluxes because the stability associated with that region resists mixing, as pointed out by Anderson and others (1996). Godfrey and Lindstrom (1989) called that region the "barrier-layer", defined by You (1998) as the vertical distance difference between a halocline and a thermocline, in which there is very little temperature change but a large salinity change.

It is believed that such a haline structure, which causes the mixedlayer to be shallow at the WPWP, works concurrently with the oceanic basin-scale circulation (warm waters being carried westward by tradewind-induced surface currents) to keep the SSTs warm in that region. However, it is not clear how the effect from the salt-stratification compares to the influence of the oceanic large-scale circulation.

In addition, both observational (WIJESEKERA et al., 1999) and modeling (COSTA et al., 2000) studies suggest that the salt-stratification can have an impact over the SSTs other than warming. Because salinity anomalies (freshwater lenses) are often produced by cold precipitation, the stabilizing effect of the salt-stratification can actually allow cooler water to sit over warmer waters, therefore favoring the occurrence of cooler SSTs.

The difficulties in investigating the intricate mechanisms by which the haline structure of the tropical oceans affect its thermal structure are evident, since they involve multiple scales. First, the formation of salinity anomalies and the maintenance of the salt-stratification depend on phenomena that occurs on spatial scales of few kilometers or less and timescales of hours or shorter, in association with atmospheric deep convection and precipitation. Second, it is plausible to think that any effect of the salt-stratification over the SSTs cannot be verified in timescales of less than a complete intraseasonal cycle, containing episodes of convection that allow the formation of a barrier-layer and suppressed periods, during which the ocean warms by absorbing solar radiation.

In this paper, a CRM is coupled to an oceanic model (COSTA et al., 2000) in order to test the hypothesis that the haline stratification favors warm SSTs over the WPWP. This modeling tool allows the full range of atmospheric spatial scales between cloud-and mesoscale to be represented in the same framework. In addition, running for a long period of time, the coupled model is able to simulate phenomena on cloud to intraseasonal timescales.

The outline of this paper is as follows: In Section 2, the coupled model is described. In Section 3, the observed case is characterized. In Section 4, a control simulation is performed, in order to verify the model 
capabilities in representing both atmospheric and oceanic variables. In Section 5, a sensitivity test is carried out, in which the salinity effect is taken out of the ocean model, and the results are compared with the ones from the simulation with full physics (salt-stratification and freshwater flux). Conclusions are presented in Section 6.

\section{THE COUPLED MODEL}

The atmospheric model used in this study is a two-dimensional, cloud-resolving version of the Regional Atmospheric Modeling System (PIELKE et al., 1992). Microphysical processes are represented by a one-moment bulk parameterization (WALKO et al., 1995), in which the water substance is divided into up to eight categories: vapor, cloud water, rain water, pristine ice, snow, aggregates, graupel and hail. Hydrometeor diameters are assumed to follow a gamma distribution. The two-stream radiation scheme is coupled with the cloud microphysics parameterization, as described by Olsson and others (1998).

Forcing terms were added to certain prognostic equations to represent the large-scale tendencies of momentum, temperature and moisture. The large-scale forcing is applied in a form similar to that proposed by Grabowski, Wu and Moncrieff (1996). The contribution of the large-scale to the horizontal velocity is calculated using a relaxation technique, in which the nudging terms are calculated from the averaged velocity components and are uniform through the model domain. For the temperature and moisture fields, forcing terms involving the contribution from both large-scale horizontal and vertical advection are added to the tendencies in the ice-liquid potential temperature and water vapor mixing ratio. A small nudging term was introduced in the thermal and moisture equations to prevent significant temperature and humidity biases.

The ocean model is a two-dimensional version of the Princeton Ocean Model (POM), described by Blumberg and Mellor (1987). The model contains prognostic equations for the zonal and meridional currents, potential temperature, salinity, turbulent kinetic energy and turbulent length scale. A splitting procedure is adopted to resolve the fast-varying external mode and the slow-varying internal mode. The turbulence closure sub-model is the level 2.5 scheme in the hierarchy described by Mellor and Yamada (1974). Long-wave radiative fluxes are evaluated at the boundary. Short-wave radiation is allowed to penetrate the ocean and is treated as a source term of heat in each level. The present radiation scheme is quite simple: no spectral dependence is considered and a single exponential attenuation is calculated for the whole radiative flux. No large-scale forcing was imposed on the ocean model.
The coupling formulation is similar to the one described by Hodur (1997). The models interchange momentum, heat and water substance. Information regarding the downward short and long-wave radiation at the ocean surface and the SSTs allows the calculation of the radiative fluxes. The ocean currents are neglected in the calculation of the surface heat and momentum fluxes.

In both simulations presented in this paper, 400 horizontal grid points and a horizontal grid spacing of $2 \mathrm{~km}$ were used in both the atmospheric and ocean models. The atmospheric vertical grid comprised 50 levels with a variable grid-spacing of $100 \mathrm{~m}$ close to the surface to $500 \mathrm{~m}$ by the model top $(21 \mathrm{~km})$. The ocean vertical grid contained 58 vertical levels with the grid-spacing varying from $2 \mathrm{~cm}$ at the surface to $5 \mathrm{~m}$ at the model bottom $(240 \mathrm{~m})$. The atmospheric model was initialized with the average soundings over the COARE IFA on O0UTC 19 December 1992. The ocean model was initialized using data collected aboard the research vessel (R/V) Moana Wave.

\section{Case description}

This research focuses on cloud-resolving simulations of tropical convection over the WPWP, using data from the Tropical Ocean Global Atmosphere - Coupled Ocean Atmosphere Response Experiment (TOGACOARE). The period chosen for this study was the 70-day interval between 19 December 1992 and 27 February 1993.

Between 19 December and 26 December, a layer of westerly winds in the lower tropospheric deepened and intensified and the flow aloft turned increasingly easterly, intensifying the vertical wind shear. The near-surface wind speed showed a generally increasing trend, while strong convective warming and drying dominated most tropospheric levels. The SST exhibited a cooling trend. Following the series of convective episodes, between 26 December 1992 and roughly 03 January 1993, very strong shear was established throughout the troposphere over the COARE IFA. Westerly winds extended up to 8-10 km during that period, with zonal wind values greater than $15 \mathrm{~ms}^{-1}$ occupying most of the layer between 2 and $6 \mathrm{~km}$ between 30 December 1992 and 02 January 1993. Concurrently, significant average wind speeds were found close to the surface, with values ranging from 6 to $8 \mathrm{~ms}^{-1}$ observed from 30 December 1992 and 02 January 1993. The peak westerly wind burst (WWB) was often characterized by weak convective warming and weak, shallow moistening, as convection was mostly suppressed over the COARE IFA. The cooling trend continued in the SSTS.

After 02 January 1993 westerly winds relaxed and shear decreased. From that date to 08 January, the surface wind speed decreased. After 06 January, a pattern of small positive values of $Q_{1}$ and 
$Q_{2}$ found was present between 02 and 06 January. Following the WWB decay, the troposphere became mostly filled with easterlies, and the vertical wind shear decreased gradually, reaching particularly small values between 10 and 12 January. Very weak near-surface winds prevailed from 08 to 15 January. $Q_{1}$ and $Q_{2}$ were generally very small between 08 and 15 January, tending to negative values. The SSTs experienced a warming tendency. After 15 January, the environmental shear and the near-surface wind speed started to increase. Positive values of $Q_{1}$ and $Q_{2}$ indicate the re-establishment of convective activity.

Between 15 and 20 January, the troposphere exhibited a moderate vertical shear, and large-scale wind speeds of about $3 \mathrm{~ms}^{-1}$ close to the surface. The large positive values of the apparent heat source and apparent moisture sink indicate the presence of intense convective activity over the COARE IFA during that period, particularly on 18 and 19 January. That brief period of convective activity under low-level easterlies was followed by an approximately 6-day period of mostly suppressed convection. Between 20 and 25 January, the low-level flow remained easterly; the middle and upper troposphere was mostly filled by weak westerlies (the layer of westerlies deepened throughout that period) with easterlies on top, close to the tropopause, while $Q_{1}$ and $Q_{2}$ were often small. Between 25 and 29 January, the low-level flow turned to westerly, with easterly winds aloft. Near-surface winds showed an increasing trend and positive values of $Q_{1}$ and $Q_{2}$ suggest the presence of convection.

Between 30 January and 02 February, a layer of low-level westerlies deepened from a height of about $3 \mathrm{~km}$ to $7 \mathrm{~km}$, with a significant easterly flow aloft, producing relatively large vertical wind shear. Nearsurface wind speeds peaked late on 30 January, reaching about $9 \mathrm{~ms}^{-1}$. Significant convective warming and drying occurred until 31 January. This episode was followed by a suppressed period, between 01 and 09 February, characterized by the presence of low-level westerlies, wind speeds on the order of 4-5 $\mathrm{ms}^{-1}$ close to the surface, and small values of $Q_{1}$ and $Q_{2}$. After 09 January, the flow over the COARE IFA showed the characteristics of convection preceding maximum low-level westerly flow.

Late during the period, typical conditions of the active phase of the MJO occurred, such as increasing westerlies, increasing near-surface winds, and strong convective warming and drying.

\section{CONTROL SIMULATION}

\section{Wind, temperature and moisture}

Since the atmospheric model was constrained to follow the observed wind, temperature and moisture, good agreement between the model results and the observations was expected, at least regarding those fields. In fact, the modeled winds agreed very well with their observed counterparts, thanks to the small relaxation timescale (one hour). Although carried out using a long nudging timescale (one day), the relaxation scheme contributed to limit the temperarure and moistures biases to relatively small values. On average, the model exhibited a cold, moist bias, with a maximum temperature deficit of about $1.1^{\circ} \mathrm{C}$ in upper levels and a maximum moisture excess on the order of $0.6 \mathrm{gkg}^{-1}$ at the atmospheric boundary layer.

\section{Cloud fields}

The modeled total condensate field and cloud fractional area followed the imposed large-scale advective tendencies of temperature and moisture. Episodes of convective warming and drying were associated with the formation of clouds as depicted in Figures 1 (time-height plot of the horizontally-averaged total condensate mixing ratio) and 2 (timeheight plot of the cloud fractional area). In those Figures, convectively active periods (as the ones on late December, mid-January and late February) correspond to the presence of deep clouds. In contrast, during suppressed periods, cloudiness is either associated with fields of shallow cumuli or virtually absent.

Figure 3 shows a comparison between the modeled cloud cover and the observations from the International Satellite Cloud Climatology Project (ISCCP) for the 70-day period between 19 December 1992 and 27 February 1993. Here, a cloudy column in the model is defined as the one containing at least one cloudy grid box, i.e., a grid box containing more than $10^{-5} \mathrm{kgkg}^{-1}$ of cloud water plus low-density ice. The model results showed, in general, good agreement with the satellite observations. With the exception of the first day of simulation, during which the model spin-up was not complete, RAMS-POM accurately simulated the observed cloud cover during the convective episodes in late December. It also provided a good representation of the reduction in cloud cover in early January, after the peak WWB, and the cloud variations in mid-February, before the passage of another ISO. At times, the model exhibited an exaggerated clearing (for instance, between 11 and 16 January) or covering (for example, between 09 and 11 January). On average, during the 70-day period, the model underestimated the cloud cover slightly; the averaged model cloud cover was 0.7341 , versus 0.8011 from the observations.

\section{Surface heat fluxes and precipitation}

The time-varying domain-averaged modeled surface heat fluxes and precipitation are shown along with their counterparts calculated from COARE IFA observations for the 70-day period between 19 December 

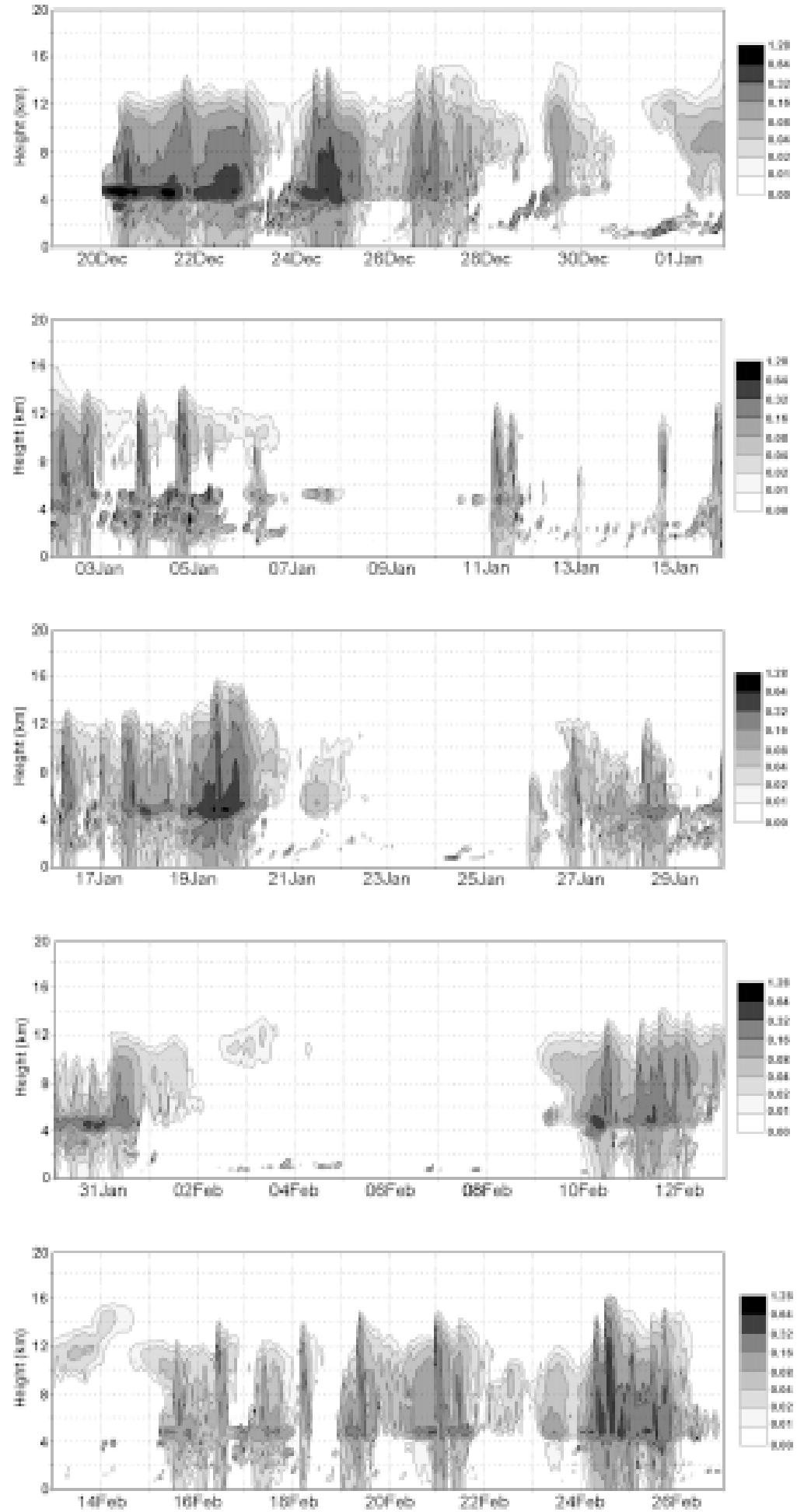

Figure 1 - Time evolution of the domain-averaged total condensate mixing ratio (in $\mathrm{gkg}^{-1}$ ) as a function of height. Contour and gray-shading intervals follow a logarithmic scale starting from $0.01 \mathrm{gkg}^{-1}$, as indicated in the scale at the right side of each plot Figura 1 - Evolução temporal da média sobre o domínio médio total de condensado (em gkg') em função da altura. Os intervalos dos contornos e os intervalos de sombreamento cinza seguem uma escala logarítmica começando em $0.01 \mathrm{gkg}^{-1}$ como indicado na barra de escala do lado direito de cada gráfico 

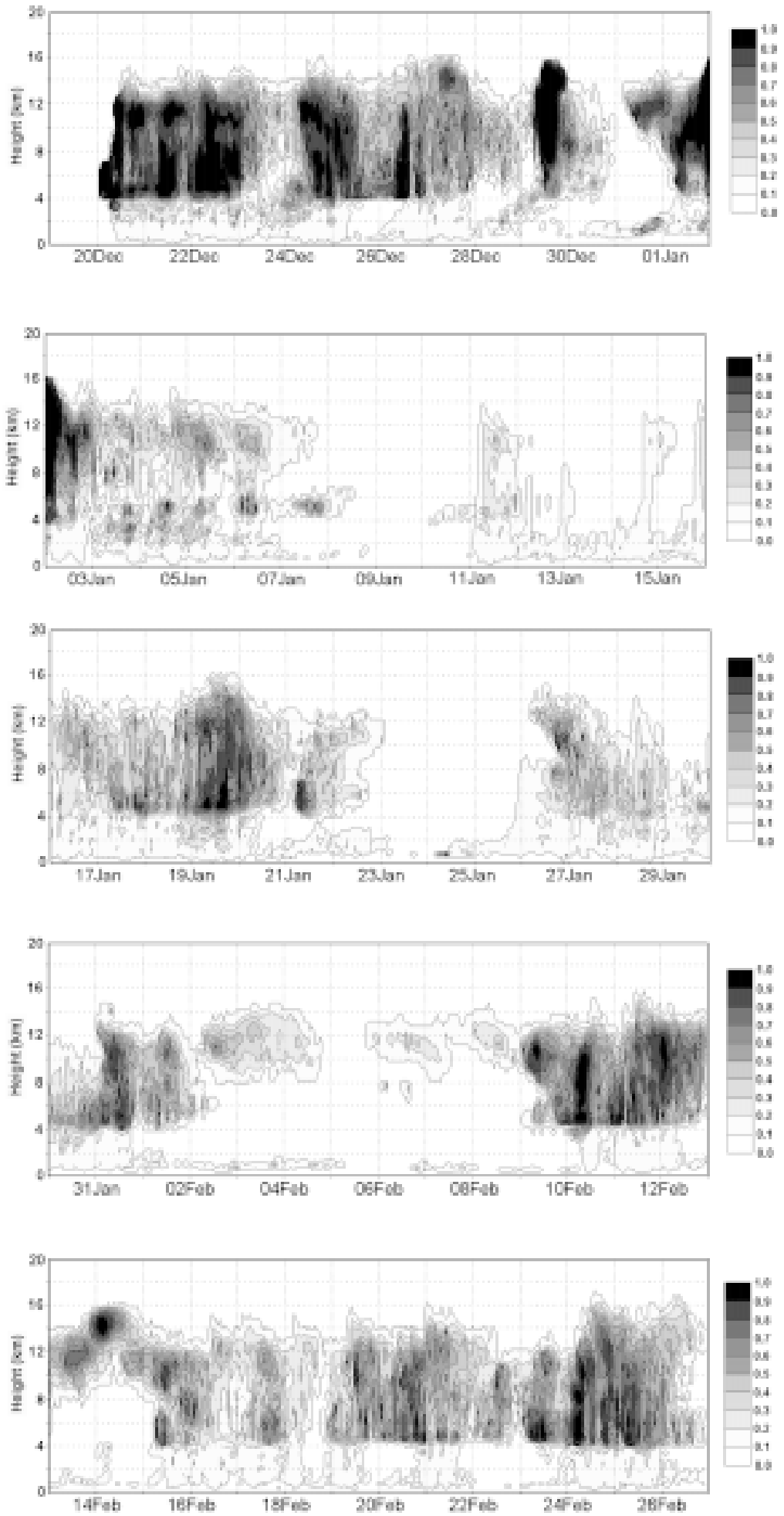

Figura 2 - Time evolution of the cloud fractional area (dimensionless) as a function of height. Contour and gray-scale shading intervals are 0.1 Figure 2 - Evolução temporal da fração de área de nuvens (adimensional) como função da altura. Os intervalos dos contornos e do sombreamento cinza são 0.1 

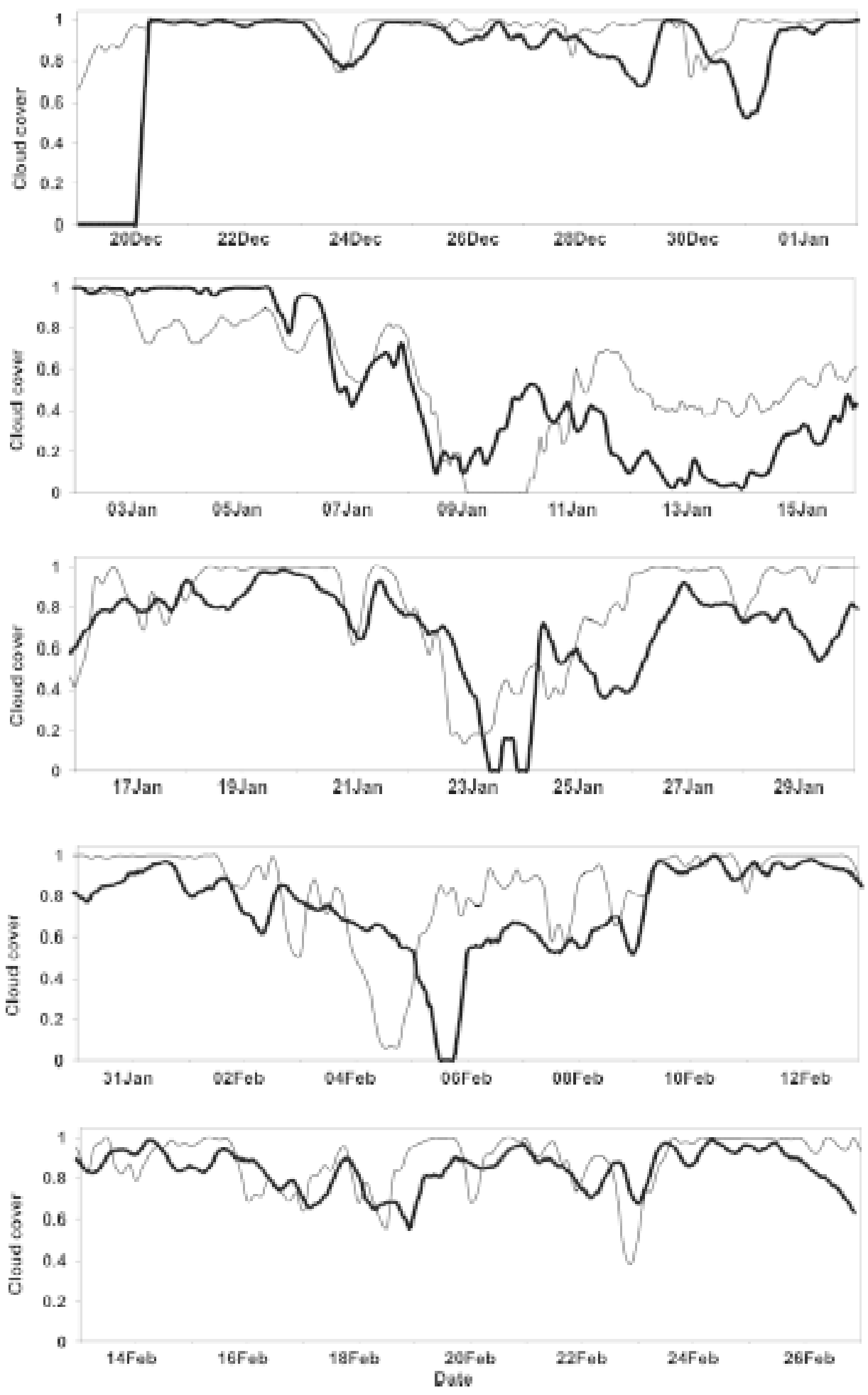

Figure 3 - Time evolution of the modeled (thick line) versus ISCCP (thin line) cloud cover over the COARE IFA between 19 December 1992 and 27 February 1993 Figura 3 - Evolução temporal da cobertura de nuvens modelada (linha grossa) contra observações do ISCCP (linha fina) sobre COARE IFA entre 19 de dezembro de 1992 e 27 de fevereiro de 1993 
1992 and 27 February 1993 in Figure 4. The first two weeks of simulation were dominated by strong convective activity, particularly between 19 and 28 December and, as discussed by Lin and Johnson (1996), the sensible heat flux peaked during the period of maximum convective activity. A strong correlation can be noted between the sensible heat flux (Figure 4a) and the precipitation field (Figure 4c). Both the precipitation and the sensible heat flux exhibit maximum values during the most pronounced convective episodes in the period between 19 and 28 December. The latent heat flux, on the other hand, maintained an increasing trend after deep convection and precipitation were suppressed, i.e., after 28 December (Figure 4b); the enhanced evaporation occurring in association with very strong westerly winds. Between 19 December and 02 January, the model was generally capable of reproducing the observed fields, except that it underestimated the major peaks in the sensible (Figure 4a) and latent (Figure 4b) heat fluxes during convective episodes, as well as the surface precipitation after 28 December (Figure $4 c$.
Between 02 and 16 January 1993, in association with reduced convective activity, the sensible heat flux was small throughout the entire 14-day period (Figure 4a). The diurnal cycle appeared as an important contributor to the variations of the sensible heat flux in time. In general, the results from the coupled simulation showed good agreement with the observations, particularly on days of suppressed convection, when the model was able to properly represent both the magnitude of the sensible heat flux and the amplitude of its diurnal variation. In early January, significant evaporation occurred in association with strong westerly winds, with observed values of the latent heat flux as high as $200 \mathrm{Wm}^{-2}$ for the average over the IFA. As the winds relaxed, the latent heat flux decreased, reaching values below $50 \mathrm{Wm}^{-2}$ less than one week later. By mid-January, evaporation increased again, with values of latent heat flux exceeding $100 \mathrm{Wm}^{-2}$. The coupled model was able to represent all those trends, although it underestimated the latent heat flux by about $20 \%$ during the peak WWB (Figure 4b). The budget precipitation was small, especially during the last 5 days of the period. The coupled model

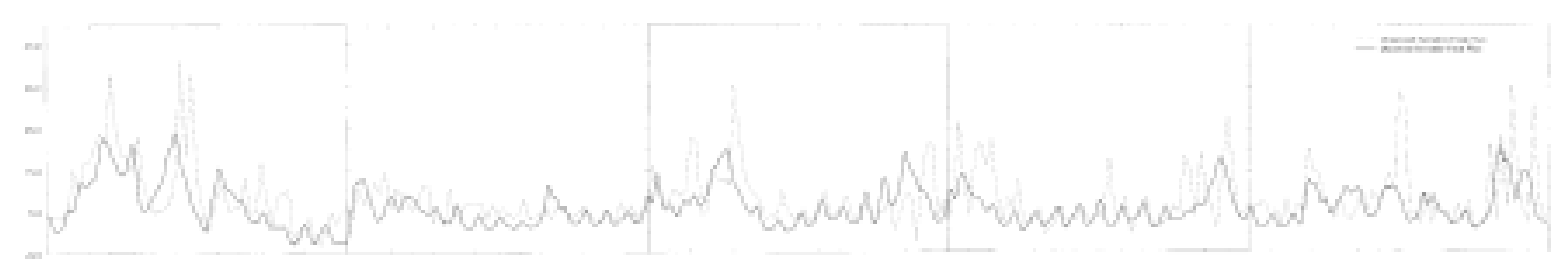

(a)

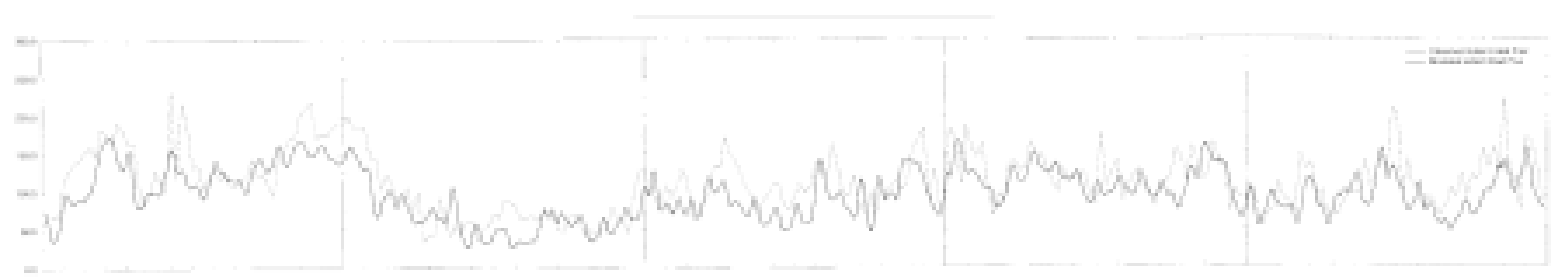

(b)

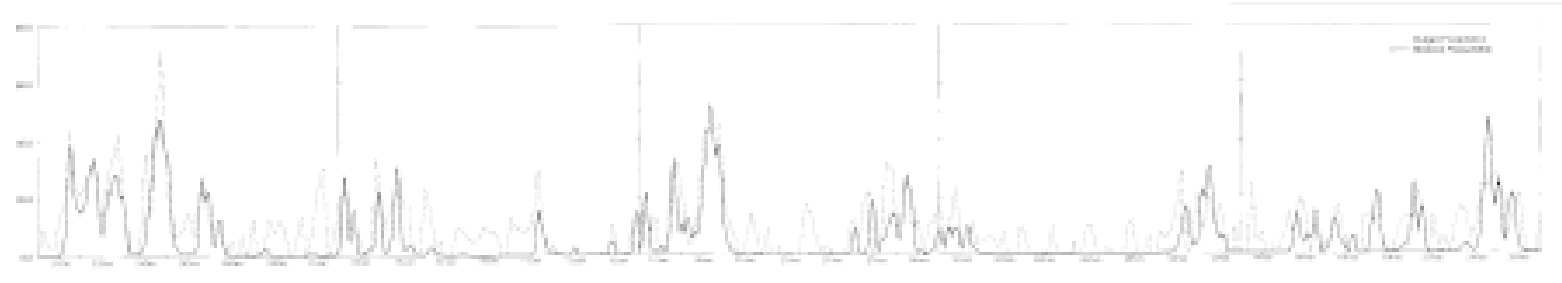

(c)

Figure 4 - Modeled (thick line) versus observed (thin line) (a) sensible heat flux, in $\mathrm{Wm}^{-2}$, (b) latent heat flux, in Wm², and (c) sufface precipitation, in mm/day ${ }^{-1}$ over the COARE IFA between 19 December 1992 and 27 February 1993

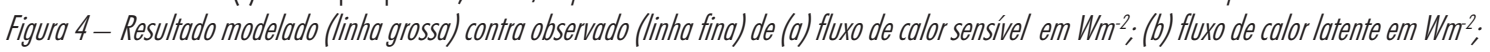
e (c) precipitaçấo à superficie em mm/dia' sobre COARE IFA entre 19 de dezembro de 1992 e 27 de fevereiro de 1993 
simulation provided values of simulated precipitation comparable to its counterparts based on observations between 02 and 05 January and after 11 January. However, it underestimated the budget precipitation in between (Figure 4c).

Enhanced sensible heat flux and significant precipitation occurred between 16 and 20 January. Following, convection was suppressed between 21 and 26 January, resulting in reduced sensible heat flux (with a clear diurnal cycle) and virtually no precipitation. The suppressed period was followed by some convective activity, accounting for the increase in the sensible heat flux and surface precipitation (Figures $4 a$ and 4c), while the surface evaporation showed peaks on 19,24, and 28 January. The first peak was associated with enhanced convective activity. The other two were related to strong surface winds.

Most of the period between 30 January and 13 February was dominated by suppressed convection. Consequently, the sensible heat flux was often small, and strongly determined by the diurnal cycle, except between 30 January and 02 February and between 09 and 13 February, as shown in Figure 4a. During the most suppressed days in this interval, the model and observed sensible and latent heat flux were in very good agreement (Figures $4 a$ and $4 b$ ). The model precipitation was approximately zero during the entire time interval, except before 01 January and after 09 February. The budget precipitation was also very small, as depicted in Figure $4 c$.

On late February, active convection developed under intensifying low-level winds. Sensible and latent heat flux and surface precipitation were highly correlated, peaking during the most convectively-active periods. Although the maxima in the surface heat fluxes were underestimated (particularly the sensible heat flux), the model was able to correctly represent the major trends in the evolution of all three variables (Figure 4).

On average, the model underestimated the surface heat fluxes, producing mean values of $6.0 \mathrm{Wm}^{-2}$ (sensible) and $96.0 \mathrm{Wm}^{-2}$ (latent). The TOGA-COARE data for the 70-day period produced average fluxes of $8.0 \mathrm{Wm}^{-2}$ (sensible) and $112.1 \mathrm{Wm}^{-2}$ (latent). The major differences between modeled and observed surface heat fluxes were found in periods of active convection, when the fluxes were often underestimated.

The model also underestimated the average IFA rainfall between 19 December 1992 and 27 February 1993, with a modeled value of $6.6 \mathrm{mmday}^{1}$ versus $8.9 \mathrm{mmday}^{-1}$ from the calculated budget. The smaller modeled precipitation is consistent with a low tropospheric moist bias and underestimated evaporation. The precipitation was generally better simulated during periods of strong large-scale forcing and deep convection. The underestimation of the precipitation produced by shallower convection can be associated with the parameterization of microphysical processes in that regime (not capable of properly simulating the development of precipitation in a low liquid water content regime), or with the horizontal grid-spacing (not fine enough to resolve circulations on the scale of shallow cumuli).

\section{Downward solar radiation}

Along with the surface sensible and latent heat flux, the other major components of the heat budget of the upper ocean are the radiative fluxes. Since the tropical oceans lose thermal energy both through longwave radiative cooling and sensible plus latent heat transfer, the absorption of solar radiation becomes the sole source to maintain the high SSTs at the warm pool. An accurate representation of the shortwave radiation flux is, therefore, strictly necessary to provide a good prediction of the upper-ocean temperatures in the context of a coupled oceanatmosphere model.

In order to verify the model capability in simulating the lowerfrequency variability of the downward shortwave radiation between 19 December and 27 February, a 5-day moving average was calculated and the corresponding result is depicted in Figure 5. The beginning of the simulated period was marked by the occurrence of a vigorous convective episode in late December 1992. As a consequence, the downward shortwave radiative flux at the surface was small, corresponding to the minimum value in the entire 70-day period. As the convective activity diminished and the cloud systems dissipated, the surface downward solar radiation experienced an increasing tendency, peaking on 16 January, according to the observations (2 days earlier, according to the coupled model). This maximum accounted for a dramatic increase in the SST, as will be shown later in this Section. Other maxima of shortwave radiative flux at the surface occurred by late January and early February.

On the average, the model slightly underestimated the net shortwave radiative flux (186.0 Wm-2, modeled, versus $196.4 \mathrm{Wm}^{-2}$, observed. The errors in the longwave radiative flux were insignificant; the model overestimating the longwave cooling at the ocean surface by $0.8 \mathrm{Wm}^{-2}$. As a result, the total radiative flux (positive downward) was underestimated by the model by $11.2 \mathrm{Wm}^{-2}$. Most of the error in the simulated shortwave radiative flux comes from periods with enhanced cloudiness, which might be due to an overestimation of radiation extinction within clouds, as calculated by the atmospheric model. 


\section{Sea Surface Temperature}

Although the ocean model was forced only by the surface fluxes (momentum, radiation, heat and precipitation), the agreement between the observed and modeled sea surface temperature was reasonable. Good results were achieved because the atmospheric model provided a surface forcing to the ocean model in agreement with the observations, and because the ocean model itself was capable of simulating important aspects of the upper-ocean dynamics in the warm pool, despite limitations due to two-dimensional geometry and the lack of large-scale oceanic forcing.

Figure 6 depicts the 5-day moving average of the observed and modeled SSTs. Most of the observed trends were well represented by the model, including the prominent warming between 06 and 16 January, and the fluctuations after 04 February 1993. It should be pointed out that all SST tendencies apparent in Figure 6 are related to the lowfrequency trends in the downward shortwave radiation shown in Figure 5 , with a phase lag ranging from one to about three days.
The only major difference between the behavior of the modeled and observed SSTs was found in the beginning of the simulation (before 06 January), when the model underestimated the cooling tendency, suggesting that the model spin-up process was not completed yet. In general, there was good agreement between observed and modeled surface temperatures at the ocean, even though processes such as largescale advection of oceanic fields were not included. It suggests that local surface forcing including radiative fluxes, and heat, momentum water substance transfer at the air-sea interface play a very significant role to the evolution of the upper ocean fields on timescales of the order of several weeks (intraseasonal variability).

On average, the model SST was slightly warmer $\left(29.35^{\circ} \mathrm{C}\right.$ versus $29.22^{\circ} \mathrm{C}$, observed). The model underestimated the sensible plus latent heat flux by $18.1 \mathrm{Wm}^{-2}$, however it also underestimated the net radiative flux by about $11.2 \mathrm{Wm}^{-2}$. The resulting difference between the modeled and observed net total heat flux $\left(6.9 \mathrm{Wm}^{-2}\right)$ is small and compatible with the warm bias $\left(0.13^{\circ} \mathrm{C}\right)$ produced by the ocean model. A warming

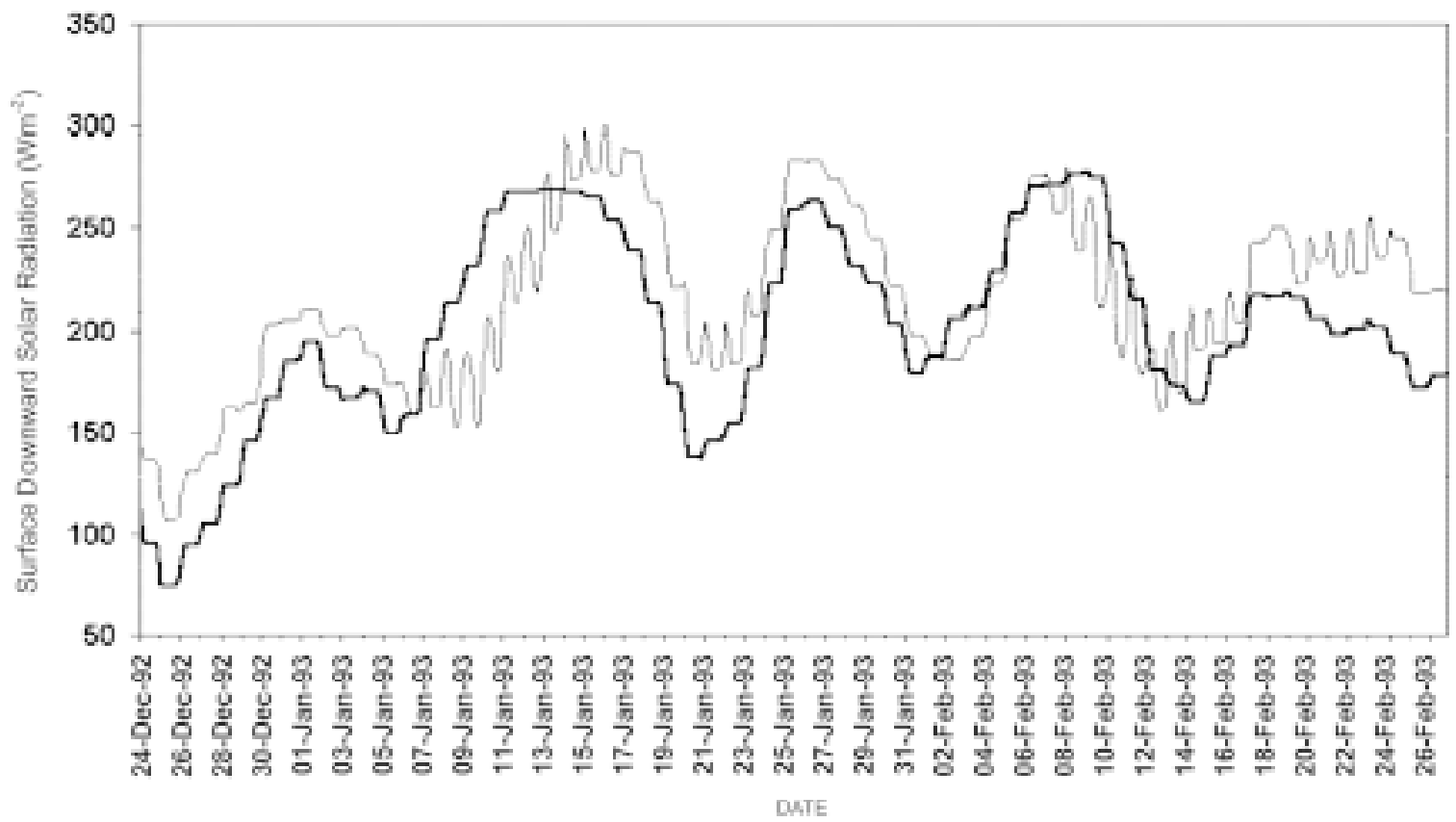

Figure 5 - Five-day moving averages of the observed (thin line) and modeled (thick line) surface downward shortwave radiation, between 19 December 1992 and 27 February 1993

Figura 5 - Médias móveis de cinco dias do fluxo incidente, na superficie, da radiação de ondas curtas observada (linha fina) e modelada (linha grossa) entre 19 de dezembro de 1992 e 27 de fevereiro de 1993 


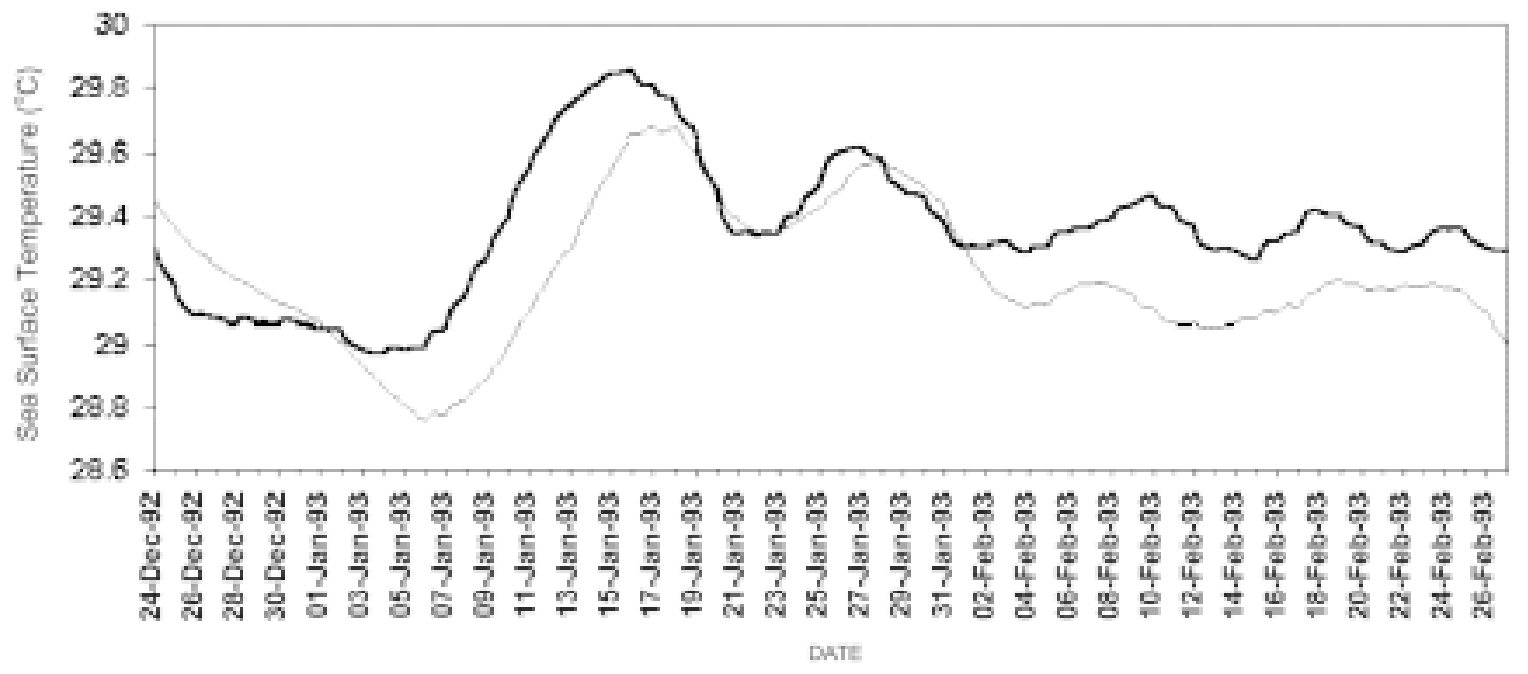

Figure 6 - Five-day moving averages of the observed (thin line) and modeled (thick line) SSTs, between 19 December 1992 and 27 February 1993 Figura 6 - Médias móveis de cinco dias das temperaturas da superficie marinha observadas (linha fina) e modeladas (linha grossa) entre 19 de dezembro de 1992 e 27 de fevereiro de 1993

effect of the same order of magnitude can be generated distributing 6.9 $\mathrm{Wm}^{-2}$ through a layer about $70 \mathrm{~m}$ deep, during a period of 70 days.

\section{SENSITIVITY TEST}

As discussed previously, some researchers argue that the saltstratification in the warm pool, with fresher water close to the surface, and a halocline shallower than the thermocline, is important to the maintenance of the large SST values over that region.

A sensitivity test was designed in order to investigate how the haline structure of the warm pool influences its thermal structure. The realistic vertical profile of salinity, based on ship measurements, used in the initialization of the model in the simulation described in the previous section, was substituted by a constant profile, with a uniform, prescribed salinity of 35.0 psu. The freshwater flux was set to zero throughout the entire simulation, so the constant salinity profile was held constant. As a consequence, the temperature was the only contributor to buoyancy effects.

The effect of ignoring salinity effects in the time mean of the domain-averaged sea surface temperature was very small. The 70-day mean of the SST in the control simulation was $29.35^{\circ} \mathrm{C}$ versus $29.38^{\circ} \mathrm{C}$ for the sensitivity experiment.

The three plots in Figure 7 provide information on how the different salinity structures influence the thermal evolution of the ocean surface. The upper panel depicts the 5-day moving average of the SST for the control and sensitivity runs. The center panel shows the difference between the SSTs in the two simulations and the corresponding 5-day moving average. The lower panel depicts the 5-day moving average of the net heat flux (positive downward), including effects of shortwave and longwave radiation and sensible and latent heat fluxes, in the two simulations.

Because the statistics of the atmospheric forcing in the two simulations were essentially the same, the SST underwent similar evolution in both cases, as shown in Figure 7a. During the suppressed phases, the two simulations produced very similar SST values, and the major differences between the simulated SSTs occurred in the two periods of active convection (late December and mid January). In both cases, the SST was higher in the sensitivity run, in disagreement with the hypothesis that salinity stratification acts to enhance the upper-ocean temperatures in the warm pool.

Figure $7 \mathrm{~b}$ shows that the maximum differences between the average SST in the two simulations are no larger than a few tenths of a degree. However, in the 5-day moving average, differences greater than $0.1^{\circ} \mathrm{C}$ were found to last for several days.

The difference between the net heat flux in the control and sensitivity runs was virtually negligible (average of $-0.56 \mathrm{Wm}^{-2}$ ), as shown in Figure 7c. It is of the same order of magnitude as the heat flux necessary to produce a temperature drop of hundredths of degrees in a 70-m deep column of water substance after 70 days but it is too small to account for the temperature differences shown in Figure $7 \mathrm{~b}$.

Analysis of Figures $7 \mathrm{~b}$ and $7 \mathrm{c}$ clarifies the physical mechanism associated with the temperature deficit in the salt-stratified case. The 

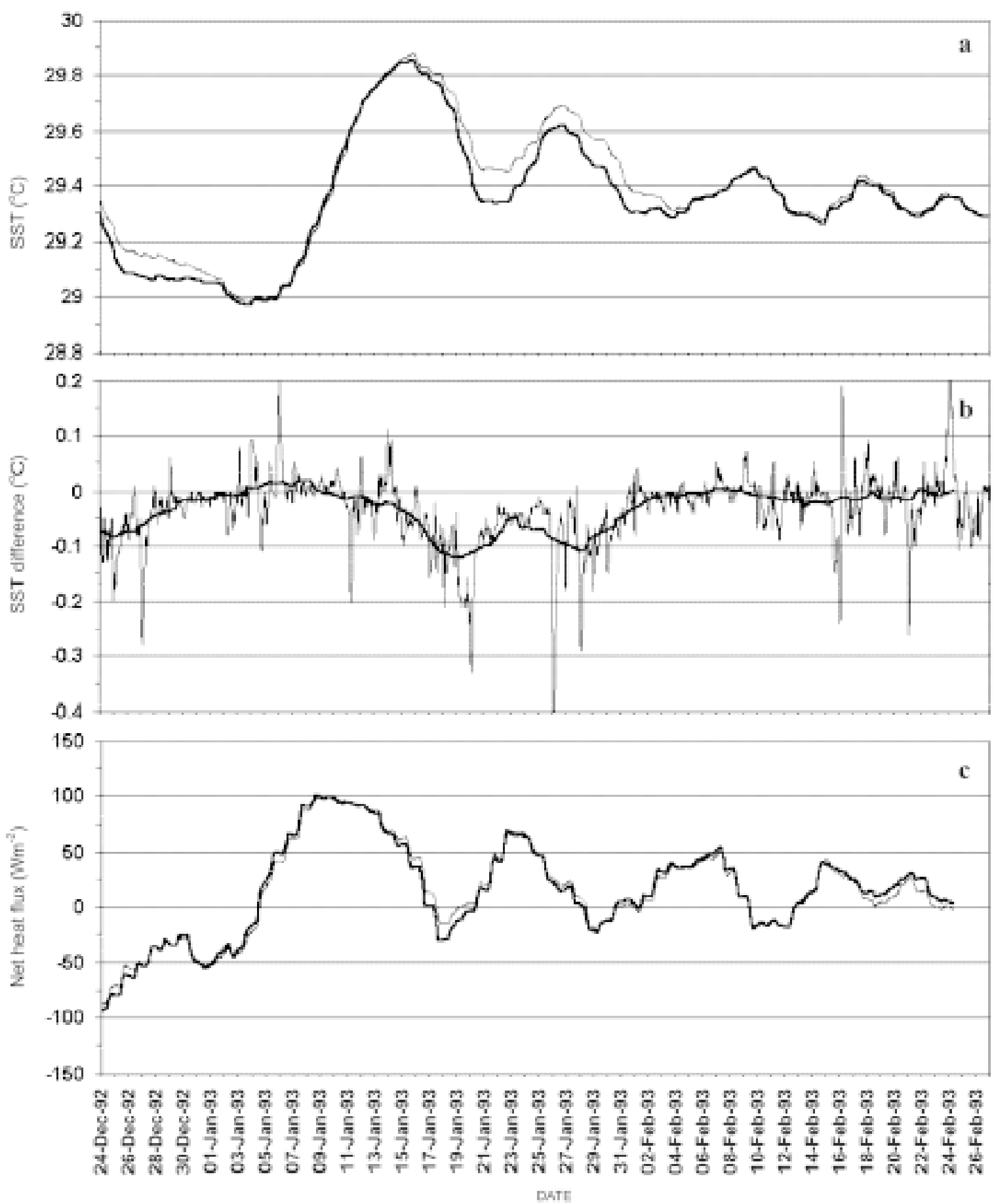

Figure 7 - (a) Five-day moving average of the SST in the control (thick line) and sensitivity (thin line) simulations of Case 3; (b) Difference between the SST in the control and sensitivity simulations (thin line) and its 5-day moving average (thick line); (c) 5-day moving average of the net heat flux in the control (thick line) and sensitivity (thin line) Case 3 simulations.

Figura 7 - (a) Média móvel de cinco dias das simulações das temperaturas da superfície do mar na simulação de controle (linha grossa) e no teste de sensibilidade (linha fina) para o caso 3; (b) diferença entre as simulações da temperatura da superficie do mar na simulação de controle e no teste de sensibilidade (linha fina) e sua média móvel de cinco dias (linha grossa); (c) média móvel de cinco dias das simulações do Caso 3 do fluxo de calor líquido no controle (linha grossa) e na sensibilidade (linha fina). 
SST in the sensitivity run is greater during periods of net surface cooling or small warming. On the other hand, when the upper ocean experiences significant net warming, the difference between the two simulated SSTs is negligible.

During active periods, large amounts of fresh water are deposited into the ocean by the precipitating systems, resulting in the production of shallow freshwater lenses that are highly stable. The strong stability of the fresh anomalies associated with the significant haline stratification allows the sustenance of an inversion in the vertical profile of temperature close to the surface. This inversion can be very strong in the fresh lenses, as reflected in the average temperature profile. Only the control simulation is able to properly represent this phenomenon. In contrast, in the sensitivity simulation, the mixing of cool rainwater with the warmer water below cannot be prevented because there is no salinity effect on the upper-ocean stability. Hence, the ocean surface tends to remain warmer than in the control case.

The difference in the thermal structure of the ocean mixed layer in the two simulations (sensitivity minus control) is shown in Figure 8. Following the first major convective episode (20 to 28 December), some differences appeared in the evolution of the ocean temperature in the two simulations. In the first panel of Figure 8, at least two layers are distinctive. In the layer above, the temperature in the sensitivity run was warmer on average. In contrast, in the layer below, the ocean temperature was greater in the control simulation. Such a dipolar structure forms because, due to the salt stratification, the upward transport of heat which opposes to the settling of cool rainwater at the ocean surface is inhibited in the control but not in the sensitivity simulation. It is apparent that, even four days after the end of the period of active convection, the ocean surface was still warmer in the simulation with no salinity effect. A similar pattern was found after 18 February.

During suppressed periods, such as between 01 and 10 February, there was virtually no difference between the upper-ocean temperature in the two simulations, particularly at nighttime. During daytime, however, under calm winds and suppressed convection, any small difference in the net surface heating rate can cause variations in the shallow, stable near-surface layer. This can be verified in the fourth panel of Figure 8. At certain days, such as 03 and 04 February, the ocean was warmer in the sensitivity simulation in the upper $10-20 \mathrm{~m}$, as opposed to 05 through 09 February, when the temperature of that layer was greater in the control run. In an average sense, the results suggest that there is no significant effect of the salt stratification in the ocean temperature during suppressed periods. During such periods, the thermal stratification appears to be dominant, at least during daytime. In fact, the presence of the highly-stable diurnal warm layer, combined with evaporation, can produce a small salinity inversion, with a saltier, warmer shallow layer sitting over the cooler, slightly fresher water in the mixedlayer below.

A better understanding of the average effect of the salt stratification on the thermal structure of the WPWP can be assessed in a composite analysis of the ocean model data for the different phases of the MJO. Three composite profiles were calculated, one for the convectively active periods, and two for the suppressed periods (daytime and nightrime). The difference between the composite temperatures in the two simulations (sensitivity minus control) is depicted in Figure 9.

Most of the differences shown in Figure 9 are extremely small, except that, during active periods, in the simulation with no salinity effect, the ocean surface was often warmer by about a tenth of a degree. This contradicts the common belief that the haline stratification at the WPWP helps the maintenance of high SSTs. In fact, our simulations suggest that the relatively fresh upper layers help the SSTs to stay at a lower temperature, by preventing mixing and the consequent destruction of the slight temperature inversion associated with the cooler precipitation.

Although the variability at the near-surface layers is greater during daytime, there is no significant influence of the diurnal cycle coupled to the salinity stratification to modify the average vertical profile of the ocean temperature. This also contradicts the viewpoint that the occurrence of high SSTs relies on the existence of a stable, fresh layer. If convection (and precipitation) is present, as discussed previously, the tendency is that the salt stratification helps the upper ocean to remain cooler. Hence, if the salinity stratification acts to favor high SSTs, it would happen primarily during periods of suppressed convection. Such a tendency was not observed in our numerical experiments.

\section{CONCLUDING REMARKS}

Air-sea processes over the Western Pacific are strongly modulated by intraseasonal modes. Eventually, the WPWP coupled system can be found in a period of suppressed convection and weak low-level winds, in which the SSTs often experience an increasing trend. In the opposing phase, organized deep convection accompanies strong evaporative and sensible cooling of the upper ocean.

In order to verify the capability of the coupled model to represent the characteristics of the atmospheric flow, including the formation of clouds and precipitation, as well as to predict accurately the oceanic fields, a 70-day simulation was performed, from 19 December 1992 to 27 February 1993. In general, the model provided results in good 

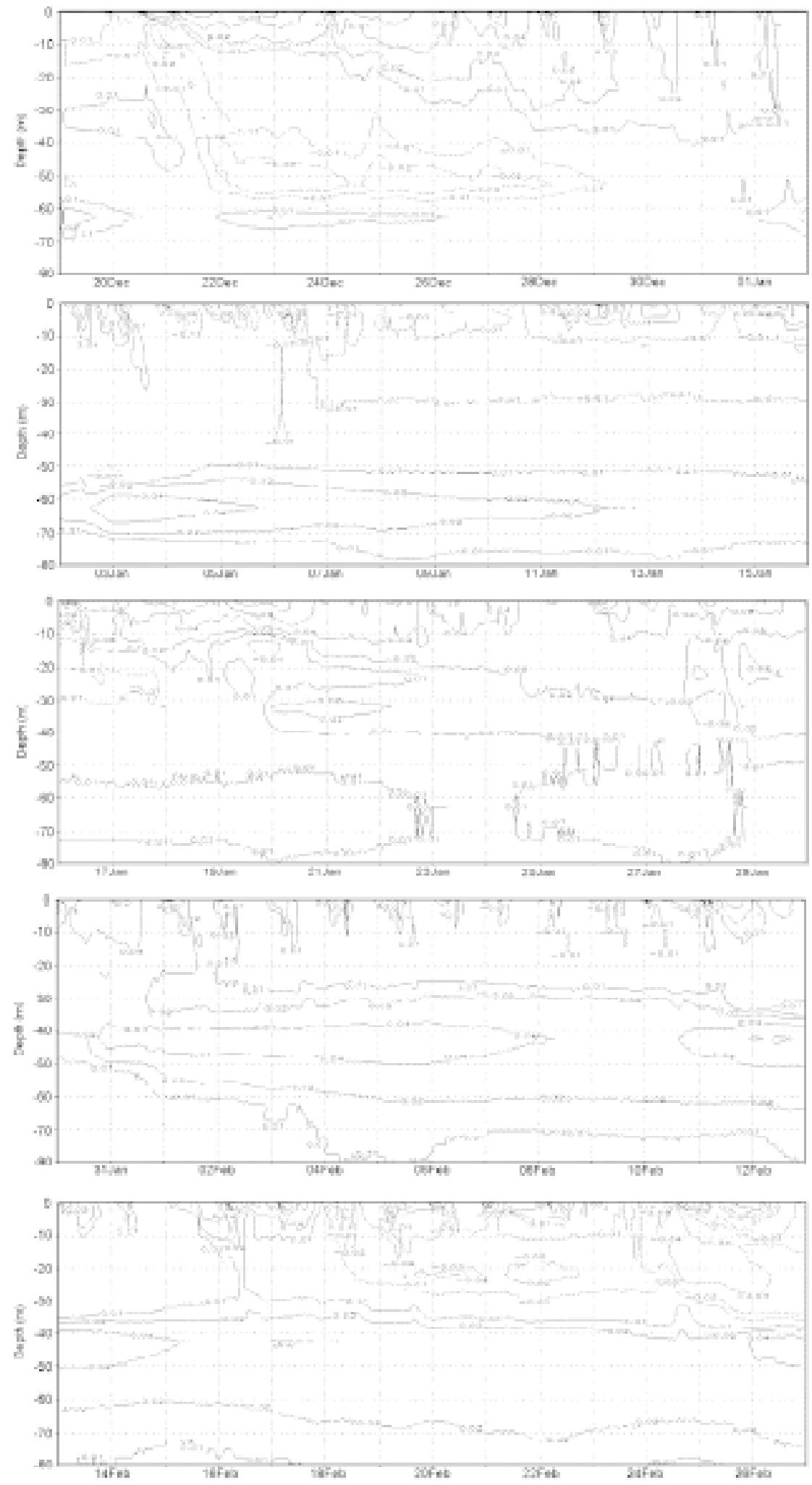

Figure 8 - Difference between the ocean temperature in the sensitivity and control simulations $\left({ }^{\circ} \mathrm{C}\right)$ in the upper $80 \mathrm{~m}$. See text for comments Figura 8 - Diferença entre a temperatura oceânica nas simulaçâes de sensibilidade e de controle (C) nos $80 \mathrm{~m}$ superiores. Ver texto para comentários 


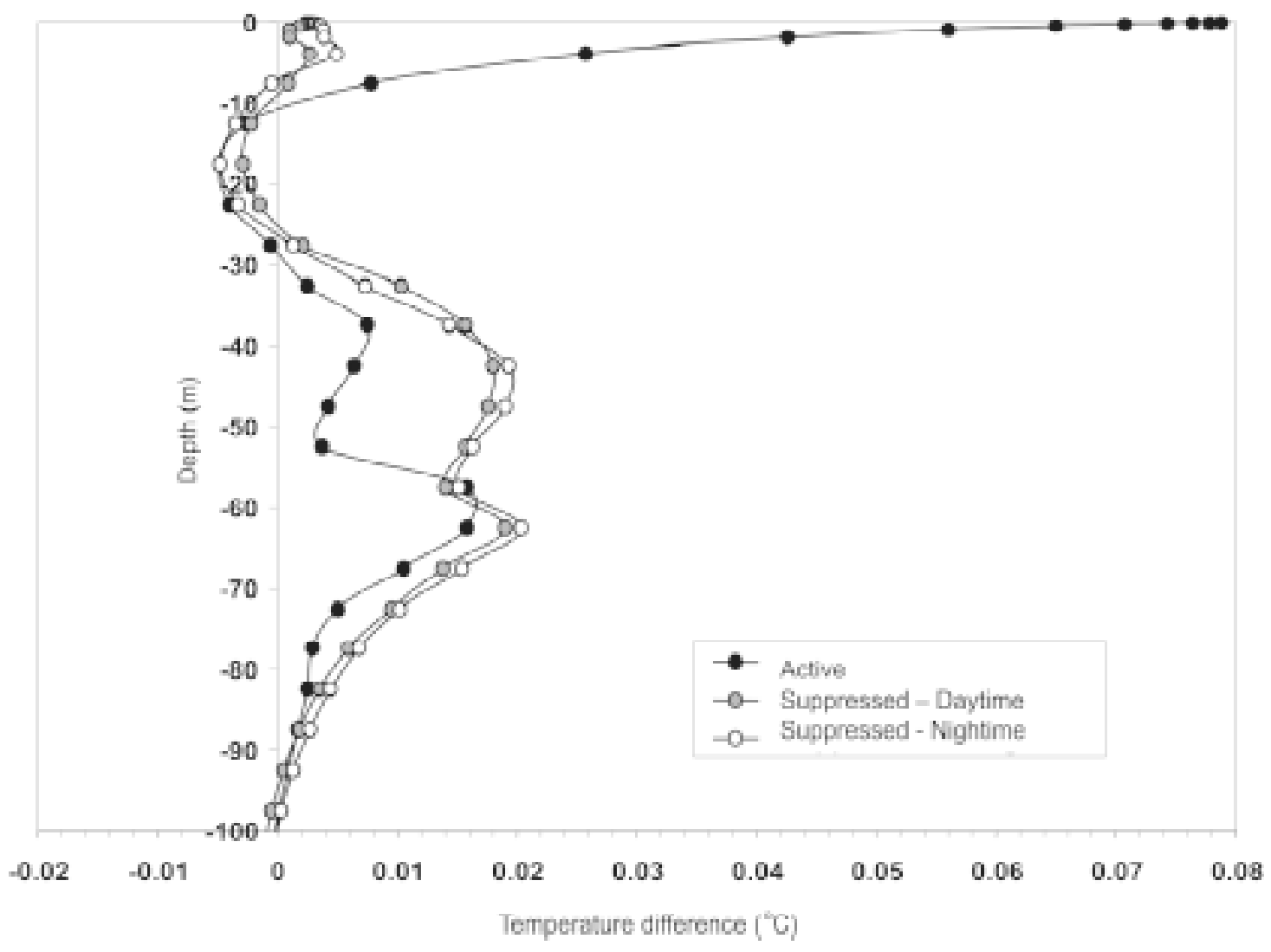

Figure 9 - Composite difference between the ocean temperature in the sensitivity and control simulations, in the upper $100 \mathrm{~m}$ for convectively active cases (black circles), daytime suppressed cases (gray circles) and nighttime suppressed cases (white circles) Figura 9 - Diferença entre a temperatura oceânica nas simulações de sensibilidade e de controle nos $100 \mathrm{~m}$ superiores para casos convectivamente ativos (círculos pretos), casos suprimidos diurno (círculos cinzas) e casos de suprimidos noturno (círculos brancos)

agreement with the observations, including cloud variables (such as cloud fractional area) observed via satellite and the ocean temperature, despite the fact that no nudging and/or advective tendencies were added to the oceanic variables.

It is possible that the use of a relatively coarse $2-\mathrm{km}$ grid spacing caused the model to underestimate the surface heat fluxes during periods of active convection. During active periods, small-scale circulations are important to enhance the transport of heat and moisture from the ocean surface. Therefore, the use of a resolution coarser than $1 \mathrm{~km}$, imposed by computer limitations in running long term coupled simulations, could affect the calculation of the fluxes primarily during convectively disturbed periods.

Since the coupled model was able to simulate the observed cloud coverage, it also provided a good estimate of the downward solar radiation, at least considering a moving average over several days. The agreement between modeled and observed fluxes of shortwave radiation allowed an accurate representation of the SST.

A longterm sensitivity experiment was performed, in which the salinity effect was ignored (in contrast to the simulation previously described that accounted for changes in salinity from precipitation and evaporation). The goal of such experiment was to test the theory that the salt stratification at the warm pool helps the maintenance of the large SST values over that region. The numerical experiment did not show any evidence to support such a theory. During active periods, when precipitating systems deposit large amounts of cool, fresh rain in the upper ocean, the haline stratification actually allowed the existence of a small temperature inversion, with cooler (but fresher) water sitting over a warmer (and saltier) mixed-layer. During suppressed periods, differences in the SST in the two simulations were indistinguishable. 
It is possible that two opposite effects, both associated with salinity, compete over the WPWP. While the so-called barrier-layer effect would act to facilitate warming at the upper ocean, the presence of stable, cool, fresh anomalies would create a shallow temperature inversion, promoting the reduction of the SST.

In order to use numerical models in the construction of a comprehensive conceptual model of the maintenance of high SSTs at the Western Pacific, as well as of its regulation, one needs to simulate basin-scale atmospheric and oceanic circulations, along with the explicit representation of the effects of clouds and precipitation in a highresolution atmosphere-ocean coupled model. Recently, Grabowski, Yano and Moncrieff (2000) showed that the present computational resources already allow the use of CRMs in the simulation of large-scale circulations over tropical oceans, at least in a two-dimensional framework. Coupling an ocean model to a large-domain CRM (which is in our plans for future research) would simultaneously allow the simulation of basin-scale and small-scale air-sea coupling.

\section{REFERENCES}

ANDERSON, S. P.; WELLER, R. A.; LUKAS, R. Surface buoyancy forcing and mixed layer of the western Pacific warm pool: observations and one-dimensional model results. Journal of Climate, Boston, v. 9, n. 12, p. 3056-3085, 1996.

BLUMBERG, A.; MELLOR, G. A Description of a three-dimensional coastal ocean circulation model.1987. Presented in $5^{\circ}$ Coastal and Estuarine Sciences, Washington, 1987.

COSTA, A. A. et al. Coupled ocean-cloud-resolving simulations of the Air-Sea Interaction over the Equatorial Western Pacific. J. Atmos. Sci., v. 58, n.22, p. 3357-3375, 2001.

FU, R. et al. Cirrus-cloud thermostat for tropical sea surface temperatures tested using satellite data. Nature, Londres, v. 358, p. 394-397, 1992. GODFREY, J. S.; LINDSTROM, E. J. The heat budget of the equatorial western Pacific surface mixed layer. J. Geophys. Res., Washington DC, v. 94 , n. C6, p. 8007-8017, 1989.

GRABOWSKI, W. W.; WU, X.; MONCRIEFF, M. W. Cloud resolving modeling of tropical cloud systems during Phase III of GATE. Part I: two-dimensional experiments. J. Atmos. Sci., Boston, v. 53, p. 3684-3709, 1996.

; YANO, J.-I.; MONCRIEFF, M. Cloud resolving modeling of tropical circulations driven by large-scale SST gradients. J. Atmos. Sci., Boston,2000. accepted.
GRAHAM, N. E.; BARNETT, T. P. Sea surface temperature, surface wind divergence, and convection over tropical oceans. Science, Washington, DC, v. 238, p. 657-659, 1987.

HODUR, R. M. The Naval Research Laboratory's coupled ocean/ atmosphere mesoscale prediction system (COAMPS). Mon. Wea. Rev., Boston, v. 125, p. 1414-1430, 1997.

LIN, X.; JOHNSON, R. H. Heating, moistening and rainfall over the western pacific warm pool during TOGA COARE. J. Atmos. Sci., Boston, v. 53, p. 3367-3383, 1996.

LINDSTROM, E. et al. The western equatorial Pacific Ocean circulation study. Nature, Londres, v. 330, p. 533-537, 1987.

LUKAS, R.; LINDSTROM, E. The mixed layer of the western equatorial Pacific Ocean. J. Geophys. Res., Washington, DC, v. 96, p. 3343-3357, 1991.

MELLOR, G.; YAMADA, T. A hierarchy of turbulence closure models for planetary boundary layers. J. Atmos. Sci., Boston, v. 31, p. 1791-1806, 1974.

OLSSON, P. Q. et al. Exploratory cloud-resolving simulations of boundarylayer Arctic stratus clouds. Part I: warm season clouds. Atmos. Res., Amsterdam, v. 47-48, p. 573-597, 1998.

PIELKE, R. A. et al. A comprehensive meteorological modeling system RAMS. Meteorol. Atmos. Phys., Viena, v. 49, p. 69-91, 1992.

RAMANATHAN, V.; COLLINS W. Thermodynamic regulation of ocean warming by cirrus clouds deduced from observations of the $1987 \mathrm{El}$ Niño. Nature, Londres, v. 351, p. 27-32, 1991.

WALISER, D. E.; GRAHAM N. E. Convective cloud systems and warmpool sea surface temperatures: Coupled interactions and self-regulation. J. Geophys. Res., Washington, DC, v. 98, p. 12881-12893, 1993.

WALKO, R. L. et al. New RAMS cloud micro-physics parameterization. Part I: the single-moment scheme. Atmos. Res., Amsterdam, v. 38, p. 29-62, 1995.

WEBSTER, P. J. The role of hydrological processes in ocean-atmosphere interactions. Rev. Geophys., Washington DC, v. 32, p. 427-476, 1994. WIJESEKERA, H. W.; PAULSON, C. A.; HUYER, A. The effect of rainfall on the surface layer during a westerly wind burst in the western equatorial Pacific. J. Phys. Oceanogr., Boston, v. 29, p. 612-632, 1999.

YOU, Y. Rain-formed barrier layer of the western equatorial Pacific warm pool: a case study. J. Geophys. Res., Washington, DC, v. 103, p. 53615378, 1998. 


\section{NOTA SOBRE O AUTOR}

Alexandre Araújo Costa é físico, com Bacherelado e Mestrado em Física pela Universidade Federal do Ceará e Doutor em Ciências Atmosféricas pela Colorado State University. Recentemente esteve à frente do grupo de pesquisadores brasileiros responsáveis por medidas de microfísica de nuvens na Amazônia, através de um avião instrumentado (campanha LBA-SMOCC-EMfiN!). É pesquisador da FUNCEME, ora desenvolvendo pesquisas na Universidade de Yale sobre o papel das queimadas na Amazônia, sobre as propriedades das nuvens e sua influência no clima. 
